\title{
Common gynecological morbidities among married women in a resettlement colony of East Delhi
}

\author{
Mansi Mathur*, Ranjan Das, Vibha
}

Department of Community Medicine, Lady Hardinge Medical College, New Delhi, India

Received: 21 July 2017

Accepted: 22 August 2017

\section{*Correspondence:}

Dr. Mansi Mathur,

E-mail: mansimathur@outlook.com

Copyright: (C) the author(s), publisher and licensee Medip Academy. This is an open-access article distributed under the terms of the Creative Commons Attribution Non-Commercial License, which permits unrestricted non-commercial use, distribution, and reproduction in any medium, provided the original work is properly cited.

\begin{abstract}
Background: A women is always celebrated for child birth but gynaecological issues a stigma is attached. The fear of being ostracised by the society for gynaecological problems is deep set. Gynaecological morbidity is defined as "structural and functional disorder of genital tract not related to pregnancy, delivery or perpuerium". This paper aims to study the pattern of gynaecological morbidity among married women residing in a resettlement colony of East Delhi.

Methods: A community based cross-sectional study was conducted during 2014-2015 in the field practise area of Lady Hardinge Medical College, New Delhi. A self-designed, pre-tested questionnaire was used to collect data. All married women of reproductive age (15-49 years) who were willing to participate were included in the study.

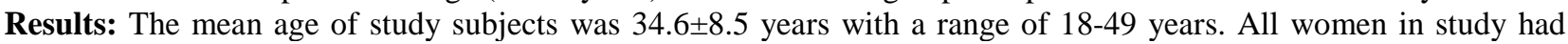
menarche within normal range (mean age $=13.1 \pm 1.01$ years, range: $11-16$ years). Mean age at marriage was $20.6 \pm 2.4$ years, range: $15-25$ years. Nearly $40 \%$ of women had 3 children and most women above 40 years of age had three or more children. The mean parity was $2.04 \pm 0.5$. Mean age at first delivery for study subjects was $22.1 \pm 3.9$ years. In the present study $722(59.5 \%)$ of the 1214 study subjects had one or more symptom related to common gynaecological morbidities. Among symptomatic 594 out of 277 (82\%) had one symptom. The commonest symptom was 'lower abdominal pain during menstrual period' 419 (34.5\%) followed by symptoms of premenstrual syndrome [(such as 'bloating' $328(27 \%)$ and 'irritability' 269 (22.2\%) and 'breast tenderness' $218(18 \%)$ ]. Other symptoms observed were 'scanty blood loss'166 (13.7\%), 'shortened duration of blood flow' $149(12.2 \%)$ and 'something coming out of vagina'140 (11.5\%).

Conclusions: Gynaecological morbidities in spite of their preponderance and adverse health outcomes, have not attracted the attention due to it for two reasons: i) women in most patriarchal dominated societies do not speak out of their health problems and needs, more so if that is not connected to the birth process, ii) Health care providers and institutions had been so overwhelmed with the birthing process, and now the expanded reproductive health issues that attending to gynaecological morbidities was considered to be "luxury" in as far as public health was considered.
\end{abstract}

Keywords: Community based study, Cross-sectional, Gynecological morbidities

\section{INTRODUCTION}

Woman is the backbone of the family and it is "she" who makes the 'house' a 'home'. Yet while for child birth she is celebrated but regarding her menstrual or sexual health she is considered imperfect, feminine and is expected to suffer in silence. So strong has been the impact of this psyche that by the time girls reached their teens, they become quite secretive about 'that time of the month' i.e. about their menstrual and sexual health even though a certain degree of openness, as far as fertility and reproduction is concerned, may be seen. 
Morbidities specific to women can broadly be classified into three major groups, namely reproductive, gynaecological and contraceptive. Gynaecological morbidity is defined as structural and functional disorder of genital tract not related to pregnancy, delivery or perpuerium. These groups of disorders, constitute a sizable proportion of disease burden in women, and are more common than reproductive and contraceptive related morbidities. They lead to considerable disability, loss of productivity, absenteeism, physical, mental and social stress, and substantial economic burden on families and individuals. Studies report that nearly one third of all healthy lives lost among adult women are due to gynaecological morbidities. ${ }^{1}$

The International Conference on Population and Development held at Cairo in 1993 added a new direction to women's health and the concept of Reproductive Health (RH) was born. In addition to pregnancy and childbirth, RH now covered the domains of fertility regulation, infertility, sexually transmitted infections and the non-sexually transmitted reproductive tract infections. But even with this new addition, RH still misses on many important domains of women's health concerns, at the individual level as well as at the population level. Of the domains being missed under the reproductive health strategy the most important are the gynaecological morbidities. GM are defined by the reproductive health research department of WHO as structural and functional disorders of genital tract not related to pregnancy, delivery or perpuerium.

Gynaecological morbidity, together with reproductive morbidity and contraceptive morbidity covers the major part of woman's health. It may also be noted that GM are among the most common of complaints and lead to considerable disability, loss of productivity, absenteeism, physical, mental and social stress, not to speak of the economic burden it causes on families and individuals. ${ }^{2}$ Studies report that nearly one third of all healthy lives lost among adult women is due to gynaecological health problems (WHO, 1995). Ignores the prevalence of many treatable conditions that cause disability and significant distress in women's lives. But also, the neglect of nonpregnant women, whether in adolescence, between pregnancies, or after menopause, means that women's health is conceptualised narrowly in terms of maternity and family planning.

Gynaecological morbidities occur in almost every woman and at much greater frequency, even though these may not cause as much mortality as delivery related issues nor do they lead to as many hospitalizations or care seeking as the STIs and RTIs. As a group while some gynaecological morbidities are already covered under the reproductive health programmes, many are not covered at all. The ones already covered belong to the infectious sub-group (namely, RTI, STI and PIDs including HIV/AIDS). Of the ones not being covered currently are the sub-categories falling in the domain of non- infectious morbidity. Predominant in this group are premenstrual syndrome, dysmenorrhoea, menstrual disturbances, dysfunctional uterine bleeding, genital prolapse, perineal lesions and infestations. ${ }^{3}$

In Indian scenario also, scant attention has been paid to the reproductive health of non-pregnant women owing to the perceived linkage of maternal health with pregnancy and childbirth and the consequent focus of the government on maternal mortality alone. Now that access to reproductive health is quite close to universal, it is time that we start focusing our attention to gynaecological morbidities also. Yet, in our country, like in most other third world countries, there is lack of information on gynaecological morbidity and there are only few studies on the topic. Existing studies give a wide range of prevalence, have been conducted under a variety of settings with few being hospital-based only or are selective for narrow groups of conditions. ${ }^{4}$ Some studies have been conducted by paramedical workers, are history based alone and sample sizes were also an issue in many of these.

Obviously, therefore, the first step would be an assessment of the problem, in terms of both magnitude, variety of problems faced by persons suffering from such morbidities. This paper aims at assessing magnitude and pattern of common gynaecological morbidities among married women (18-49 years) residing in a resettlement colony of East Delhi.

\section{METHODS}

Kalyanpuri Resettlment Colony is located in East Delhi at a distance of $12.2 \mathrm{Km}$ from Lady Hardinge Medical College (LHMC) which is one of the field practice area (Urban Health Centre) of Department of Community Medicine. The colony has a total estimated population of 25,754 (as per survey done in Department of Community Medicine, LHMC, 2011) residing in 11 blocks, each having 1000 to 3000 population approximately. Residential colonies around the study area are Khichdipur, Trilokpuri and Mayur Vihar-1. The area is well connected to other parts of Delhi by public transport system such as metro, buses and autos. The educational facilities available in this area include a Government primary and a senior secondary school besides two private schools. The colony is also covered under the Integrated Child Development Scheme (ICDS). The services are provided through 26 anganwadis with 1-2 anganwadis in each block.

Health care is available to the residents of Kalyanpuri through government institutions, private medical practitioners and nursing homes. There are five government health facilities in Kalyanpuri. Primary care services are provided by

- Urban Health Centre of Department of Community Medicine, Lady Hardinge Medical College, 
- East Delhi Municipal Corporation (EDMC) dispensary,

- Mother and Child Welfare Centre by the name of Danveer Bhamashah Prasuti Grah,

- Delhi Government Dispensary, Lal Bahadur Shastri hospital which provides secondary level health care.

The study was conducted from November 2013 to March 2015. Data was collected from $1^{\text {st }}$ January 2014 to $31^{\text {st }}$ December 2014.

\section{Inclusion criteria}

Married women of reproductive age (15-49 years) who were willing to participate in the study.

\section{Exclusion criteria}

All pregnant women and those not willing to participate.

Sample size $(\mathrm{N})$ was calculated using formula $\mathrm{N}=4 \mathrm{pq} / \mathrm{L} 2$, where $\mathrm{p}$ is in this case being prevalence of common gynecological morbidities, $\mathrm{q}$ is $1-\mathrm{p}, \mathrm{L}$ is allowable error taken as $10 \%$ of $\mathrm{p}$. Based on prevalence of $30 \%$ obtained from previous studies, sample size was worked out to be 933. Since the list of eligible study population was not available it was decided to take a sample of 933 houses expecting at least one subject likely to be available in each house.

The total population 25,754 of Kalyanpuri resides in 11 blocks numbered from 11-21. All the blocks were included in the study and number of sample houses in each block was worked out by using the Probability Proportionate to size (PPS). Selection of houses was done by simple random sampling technique using EpiInfo software version 7. All married women in the age group of 15-49 years from the selected houses were included in the study so as to get the required sample size.

Data for study was collected from married women in reproductive age group using a semi-structured questionnaire which was designed and pretested to collect information on socio-demographic profile, reproductive profile, common gynecological morbidities and treatment seeking behavior. The proforma included:

- Interview

- Clinical history, relevant general and systemic examination

- Gynecological examination

- Microbiological investigations

\section{Data collection}

All the selected 933 houses were visited to enlist the married women between 15-49 years of age. Eligible subjects were explained the purpose and methodology of the study. Those willing to participate were enrolled after taking written informed consent. All efforts were made to minimize refusal for participation.

Data was collected using the above-mentioned instrument. Interview and physical examination were conducted at homes of enrolled study subjects. Women with symptoms suggestive of gynecological morbidities were requested to visit Urban Health Centre, Kalyanpuri for gynecological examination and microbiological investigation.

\section{RESULTS}

\section{Sociodemographic profile}

The mean age of study subjects was $34.6 \pm 8.5$ year with a range of $18-49$ years. Almost one third $(389 ; 32.0 \%)$ of women were in the age group of 25-29 years (Table 1), the high proportion in this age group could be due to the small sample size as well as migration of young people to the study area.

Most of the women were Hindus (97.6\%) while Muslims were $(2.0 \%)$, Sikhs and Christians $(0.04 \%)$ were in small proportion.

Table 1: Common gynecological morbidity in study subjects according to age.

\begin{tabular}{|llllllll|} 
Age in years & $\mathbf{N}$ & Dysmenorrhoea & $\begin{array}{l}\text { Menstrual } \\
\text { problems }\end{array}$ & $\begin{array}{l}\text { Premenstrual } \\
\text { syndrome }\end{array}$ & $\begin{array}{l}\text { Prolapse } \\
\text { Abnormal vaginal } \\
\text { discharge }\end{array}$ & $\begin{array}{l}\text { Local } \\
\text { lesions and } \\
\text { infestations }\end{array}$ \\
& & No. $(\%)$ & No. $(\%)$ & No. $(\%)$ & No. $(\%)$ & No. $(\%)$ & No. $(\%)$ \\
\hline $15-19$ & 4 & $1(25.0)$ & $1(25.0)$ & $2(50.0)$ & 0 & 0 & $1(25.0)$ \\
\hline $20-24$ & 111 & $1(0.9)$ & $2(1.8)$ & $50(45.0)$ & 0 & $2(1.8)$ & $5(4.5)$ \\
\hline $25-29$ & 389 & $262(67.3)$ & $39(10.0)$ & $59(15.1)$ & 0 & $10(2.5)$ & $9(2.3)$ \\
\hline $30-34$ & 128 & $74(57.8)$ & $15(11.7)$ & $93(72.6)$ & 0 & $9(7.0)$ & $11(8.5)$ \\
\hline $35-39$ & 111 & $60(54.0)$ & $54(48.6)$ & $84(75.6)$ & 0 & $12(10.8)$ & $16(14.4)$ \\
\hline $40-44$ & 267 & $21(7.8)$ & $156(58.4)$ & $27(10.1)$ & $86(32.2)$ & $20(7.4)$ & $7(2.6)$ \\
\hline $45-49$ & 204 & 0 & $88(43.1)$ & $15(7.3)$ & $54(26.4)$ & $21(10.2)$ & $9(4.4)$ \\
\hline Total & 1214 & $419(34.5)$ & $355(29.2)$ & $328(27.0)$ & $140(11.5)$ & $74(6.0)$ & $57(4.6)$ \\
\hline
\end{tabular}




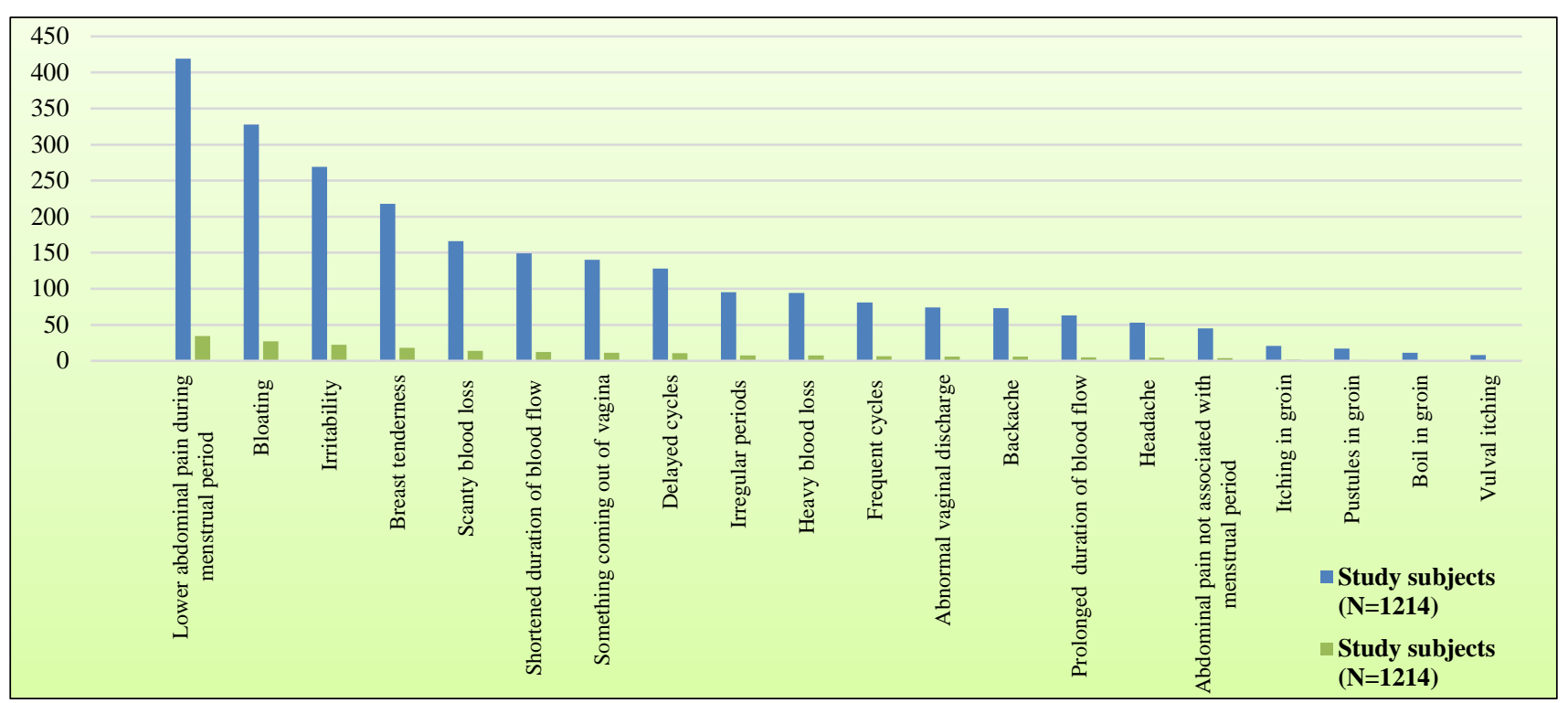

Figure 1: Common gynaecological symptoms.

Table 2: Gynaecological morbidities present in study subjects based on history and / or clinical examination and microbiological investigation.

\begin{tabular}{|c|c|c|}
\hline \multirow{2}{*}{ Gynaecological morbidity* } & \multicolumn{2}{|c|}{ Study subject $N=1214$} \\
\hline & No. & $\%$ \\
\hline Dysmenorrhoea & 419 & 34.5 \\
\hline Menstrual disorder & 355 & 29.4 \\
\hline Hypomenorrhea & 166 & 46.7 \\
\hline Menorrhagia & 94 & 26.4 \\
\hline Oligomenorrhoea & 83 & 23.3 \\
\hline Metrorrhagia & 12 & 3.3 \\
\hline Premenstrual syndrome & 328 & 27.0 \\
\hline Prolapse & $140 \#$ & 11.0 \\
\hline First degree & 33 & 25.3 \\
\hline Second degree & 94 & 72.3 \\
\hline Third degree & 3 & 2.3 \\
\hline Abnormal vaginal discharge & 74 & 5.9 \\
\hline Bacterial vaginosis & 34 & 66.6 \\
\hline Vaginal candidiasis & 17 & 33.4 \\
\hline Local perineal lesion/infestation & 57 & 4.6 \\
\hline Intertrigo & 19 & 33.3 \\
\hline Folliculitis & 16 & 28.0 \\
\hline Furuncle & 11 & 19.2 \\
\hline Pubic lice & 2 & 3.5 \\
\hline Scabies & 1 & 1.7 \\
\hline Reproductive tract infection & 102 & 8.4 \\
\hline Cervical erosion & 54 & 52.9 \\
\hline Uterine tenderness & 21 & 20.5 \\
\hline Fornicial thickening & 21 & 20.5 \\
\hline Cervical hypertrophy & 6 & 5.8 \\
\hline $\begin{array}{l}\text { *Multiple response; \#10 subjects di } \\
\text { hence degree of prolapse could not } \\
\text { was commonest followed by } \mathrm{I}^{\circ} \text {; Vas } \\
\text { microbiologically, and bacterial } \\
\text { Intertrigo was the commonest peri } \\
\text { followed by folliculitis }\end{array}$ & $\begin{array}{l}\text { not co } \\
\text { e asce } \\
\text { nal dis } \\
\text { ginosi } \\
\text { eal les }\end{array}$ & $\begin{array}{l}\text { xamination } \\
\text { II }{ }^{\circ} \text { prolapse } \\
\text { as assessed } \\
\text { xammonest } \\
\text { xamination }\end{array}$ \\
\hline
\end{tabular}

In the study area $550(45.3 \%)$ of the study subjects were educated up to high school and above; 223 (18.4\%) of the women were illiterate. $729(60 \%)$ of the study subjects were home makers while $40 \%$ of study subjects were employed outside. Majority of study subjects belonged to nuclear families $(961 ; 79.2 \%)$. Most of the study subjects belonged to upper lower socioeconomic status (599; $49.3 \%)$ and lower middle $(401 ; 33.0 \%)$ class based on modified Kuppuswamy score using consumer price index correction for 2014. Studies on related subject have varied sociodemographic profile and have used modified Prasad classification.

\section{Obstetric profile and contraceptive use}

All women in study had menarche within normal range (mean age $=13.1 \pm 1.01$ years, range: $11-16$ years). Present findings were similar to mean age at menarche 13.1 years observed by Pandit et al (32\%) in a crosssectional study conducted in an urban slum of Mumbai. ${ }^{5}$

Mean age at marriage (20.6 \pm 2.4 years range: $15-25$ years) was found similar to that (urban-21.8) reported by DLHS-3 (2007-2008) for Delhi. ${ }^{6}$ Nearly $40 \%$ of women had 3 children and most women above 40 years of age had three or more children. The mean parity was $2.04 \pm 0.5$.

Mean age at first delivery for study subjects was $22.1 \pm 3.9$ years. It was observed that $684(57 \%)$ of the study subjects delivered their first child between 20-24 years. Nearly half of the study subjects 549 (45.7\%) had all deliveries in hospital where as 285 (23.7\%) had all home deliveries. Findings in surveys and various studies have shown varying proportions of deliveries conducted in hospital. In many of these studies the reference periods were different viz. delivery in last three years or last three 
deliveries but in the current studies all deliveries have been taken into account.

DLHS-3 (2007-2008) for Delhi reports $69.6 \%$ of institutional deliveries and $42.6 \%$ home deliveries in last three years; while Elizabeth et al reported last 3 deliveries as $43.1 \%$ institutional and $56.9 \%$ at home. ${ }^{7}$ Due to the different reference periods the results may not be comparable. More than half $658(54 \%)$ of study subjects underwent one or more caesarean section or assisted vaginal delivery while the rest $542(45.5 \%)$ had all normal vaginal deliveries.

In the present study $664(54.6 \%)$ subjects were currently using some method of contraception which was similar to that $(55.7 \%)$ reported by DLHS-3 for Delhi. The proportion of condom user was $514(42.3 \%)$ higher in the current study as compared to $21.9 \%$ in DLHS-3. IUD, OCP and female sterilisation also differed being 22 $(1.8 \%), 1(0.1 \%)$ and $127(10.4 \%)$ in the present study viz. $5 \%, 4.9 \%$ and $22.9 \%$ in DLHS-3, respectively. The differences in type of contraceptive use could be attributed to the differences in current parity and in age structure of the study subjects. Besides the differences in ages being studied (15-49 years in current study and 1544 in DLHS-3).

\section{DISCUSSION}

In the present study $722(59.5 \%)$ of the 1214 study subjects had one or more symptom related to common gynecological morbidities; this was higher than that observed $(24.4 \%)$ by Kambo et al in a community based multi centric study (14 states, 23 districts) but was lower than $(88 \%)$ that reported by Garg et al in an urban slum of Delhi. ${ }^{8,9}$ In the current study, among symptomatic 594 out of $277(82 \%)$ had one symptom which was higher than that reported by Kambo et al $(75 \%)$ and by Elizabeth et al $(46.5 \%)$. The variation in gynecological morbidities may be due to differences in age and population profile of subject.

In the current study the commonest symptom was 'lower abdominal pain during menstrual period' 419 (34.5\%) followed by symptoms of premenstrual syndrome (such as 'bloating' $328(27 \%)$ and 'irritability' $269(22.2 \%)$ and 'breast tenderness' 218 (18\%). Other symptoms observed were 'scanty blood loss' $166(13.7 \%)$, 'shortened duration of blood flow' $149(12.2 \%)$ and 'something coming out of vagina' 140 (11.5\%).

Various studies have reported different symptoms, Gosalia et al in a community based cross-sectional study in urban slums of Bhavnagar reported reproductive tract infections (26.4\%), menstrual problems (26\%), dysparenuia $(2.7 \%)$ and prolapse $(00.4 \%) .{ }^{10}$

Inamdar et al in a community based cross sectional study in Nanded city reported menstrual disorders (50.5\%), reproductive tract infections $(27.1 \%)$, prolapse $(16.4 \%)$ and cervical dysplasia $(8.7 \%)$ as most common symptoms. ${ }^{11}$

The following are the strengths of the study:

- Community based study with scientifically calculated sample size

- Study subjects were selected by simple random sampling technique from all the 10 blocks within the field practice area of UHC Kalyanpuri

- Common gynaecological morbidities were assessed based on history and clinical examination and confirmation was attempted through microbiological examination.

Assessment of symptoms of gynecological morbidity was primarily based on history

- It is likely that history taking might have missed some of the symptoms

- Working case definitions used by us may also have missed out some of the symptoms of gynaecological morbidities

- Clinical Examination and Microbiological investigations could not be done for all since in spite of best efforts many did not come for gynaecological examination nor gave consent for investigations

- Patients in the initial stages of their problem or having very mild problems might have been missed out

- Confirmation of the gynaecological symptoms or morbidities could not be done

- All above points might have altered the picture of our observations

- Only one interaction with the study subjects does not give enough time to build rapport over sensitive and personal issues.

\section{CONCLUSION}

To sum up, gynaecological morbidities in spite of their preponderance and adverse health outcomes, have not attracted the attention due to it for two reasons: i) women in most patriarchal dominated societies do not speak out of their health problems and needs, more so if that is not connected to the birth process, ii) Health care providers and institutions had been so overwhelmed with the birthing process, and now the expanded reproductive health issues that attending to gynaecological morbidities was considered to be "luxury" in as far as public health was considered..

\section{Recommendations}

Mechanisms for identifying symptoms of gynaecological morbidities as well as the morbidities themselves among non-pregnant women of reproductive age at primary care level needs to be developed owing to the high burden of this group of conditions $(59.5 \%)$ 
Health care providers must be cautious about the six common gynaecological morbidities, namely, dysmenorrhoea, menstrual problems, premenstrual syndrome, prolapse, abnormal vaginal discharge and local perineal lesions and infestations which emerged as a big contributor of morbidity in this population.

Funding: No funding sources Conflict of interest: None declared

Ethical approval: The study was approved by the Institutional Ethics Committee

\section{REFERENCES}

1. Jeejeebhoy SJ, Rao R. Unsafe motherhood A review of reproductive health in India, paper presented at the workshop on Health and development in India, sponsored by the National Council of Applied Economic Research and Harvard University, Centre for Population and Development Studies, New Delhi, 2-4 January 1992.

2. Bang RA, Baitule M, Sarmukaddam S, Bang AT, Choudhary Y, Tale O. High prevalence of gynaecological diseases in rural Indian women. The Lancet. 1989;333(8629):85-7.

3. Mali S, Wahi PN, Luthra UK. Cancer of the uterine cervix. Ind J Cancer. 1968:269-73.

4. Sai FT. Safe motherhood initiative: A call for action. IPPE Bull. 1987;21:3.

5. Pandit SD, Prabha R, Shanbag S. Morbidity pattern of women attending screening program in an urban slum in Mumbai. Indian $\mathbf{J}$ Commun Med. 2005;30:134-5.

6. International Institute for Population Sciences (IIPS), 2010. District Level Household and Facility Survey (DLHS-3), 2007-08: India. Mumbai: IIPS.

7. Elisabeth AM, Bir T. Self- reported gynecological morbidity and treatment seeking behavior among rural women of state of Uttarakhand in India: call for NGOS action. Int J Dev Res. 2014;4(11):2540-6.

8. Garg S, Sharma N, Bhalla P, Sahay R, Saha R, Raina $\mathrm{U}$, et al. Reproductive morbidity in an Indian urban slum: Need for health action. Sex Transm Infect. 2002;78:68-9.

9. Kambo IP, Dhillon BS, Singh P, Saxena BN, Saxena NC. Self-reported gynecological problems from twenty three districts of India (An ICMR task force study). Indian J Community Med. 2003;28(2):67-73.

10. Inamdar IF, Priyanka S, Doibale MK. Gynaecological morbidities among ever married women: a community based study in Nanded city, India. J Dental Med Sci. 2013;7(6):5-11.

11. Gosalia VV, Verma PB, Doshi VG, Singh M, Rathod SK, Parmar MT. Gynecological Morbidities in women of reproductive age group in urban slums of Bhavnagar city. Natl J Commun Med. 2012;3(4):657-60.

Cite this article as: Mathur M, Das R, Vibha. Common gynecological morbidities among married women in a resettlement colony of East Delhi. Int $\mathbf{J}$ Reprod Contracept Obstet Gynecol 2017;6:5330-5. 